GOMES, RF; CRUZ, FJR; NUNES, RC; CASTOLDI, R; SANTOS, DMM; BRAZ, LT. 2016. Respostas enzimáticas na enxertia de tomateiro. Horticultura Brasileira 34: 491-497. DOI - http://dx.doi.org/10.1590/S0102-053620160407

\title{
Respostas enzimáticas na enxertia de tomateiro
}

\author{
Rafaelle F Gomes ${ }^{1}$; Flávio JR Cruz²; Renata C Nunes ${ }^{3}$; Renata Castoldi'; Durvalina MM Santos ${ }^{2}$; Leila T \\ Braz $^{2}$ \\ ${ }^{1}$ Universidade Federal Rural da Amazônia (UFRA), Capanema-PA, Brasil; rafaelle.fazzi@yahoo.com.br; ${ }^{2}$ Universidade Estadual Paulista \\ (UNESP/FCAV), Jaboticabal-SP, Brasil; fjrc@bol.com; dumaria@fcav.unesp.br; leilatb@fcav.unesp.br; ${ }^{3}$ Universidade Estadual de \\ Londrina (UEL), Londrina-PR, Brasil; renatacastronunes@gmail.com; ${ }^{4}$ Universidade Federal de Uberlândia (UFU), Monte Carmelo- \\ MG,Brasil; rcastoldi@ufu.br
}

\section{RESUMO}

Visando avaliar a compatibilidade de tomateiros enxertados em diferentes portaenxertos, sob ambiente protegido, foi determinada a atividade das enzimas antioxidantes, peroxidases (POXs), polifenoloxidase (PPO) e superóxido dismutase (SOD). A primeira etapa experimental consistiu na avaliação, aos seis e onze dias após a enxertia, das mudas enxertadas e não enxertadas com três combinações de enxertia (Maxifort, Multifort e autoenxertia), em três regiões de coleta no caule: a) $2 \mathrm{~cm}$ acima da região da enxertia; b) na região de enxertia e c) $2 \mathrm{~cm}$ abaixo da região da enxertia, além do tratamento adicional, constituído de mudas não enxertadas de 'Alambra' (pé franco). $\mathrm{O}$ delineamento experimental foi inteiramente casualizado, em esquema fatorial $3 \times 3+1$, com cinco repetições. Na segunda etapa experimental houve o transplantio das mudas para a casa de vegetação, com as combinações de enxertia 'Maxifort', 'Multifort', autoenxertia e pé franco, considerando nas parcelas as combinações da enxertia e nas subparcelas os quatro períodos de coleta 30,60 , 90 e 120 dias após o transplantio. O delineamento experimental foi em blocos ao acaso, em esquema de parcela subdividida, sendo cada parcela experimental constituída de seis plantas, com seis repetições. Os resultados da primeira etapa mostram que houve incremento na atividade das POXs e PPO durante o pegamento das enxertias com os portaenxertos 'Maxifort', 'Multifort' e também na autoenxertia. $\mathrm{Na}$ segunda etapa, observou-se maior incremento na atividade de SOD e POXs para o portaenxerto 'Multifort' aos 120 dias após o transplantio. As plantas enxertadas e o pé franco não apresentaram indícios de incompatibilidade, sendo o aumento da atividade enzimática atribuído ao processo de cicatrização e lignificação das mudas enxertadas, tendo mantido esse comportamento ao longo do ciclo de crescimento e desenvolvimento das plantas de tomateiro. A produção por planta não sofreu influência da enxertia.

Palavras-chave: Solanum lycopersicum, compatibilidade, superóxido dismutase, peroxidases, polifenoloxidase.

\section{ABSTRACT}

\section{Enzymatic responses on tomato grafting}

To evaluate the compatibility of tomato plants grafted onto different rootstocks under greenhouse conditions, the activity of antioxidant enzymes, peroxidases (POXs), polyphenol oxidase (PPO) and superoxide dismutase (SOD) were determined. The first experimental step was to assess, at six and eleven days after grafting, the grafted seedlings and non-grafted ones with three combinations of grafting (Maxifort, Multifort and selfgraft) in three collecting regions in the stem: a) $2 \mathrm{~cm}$ above the grafting region; b) on the grafting region c) $2 \mathrm{~cm}$ below the grafting region, in addition to further treatment, consisting of ungrafted seedlings of 'Alambra'. The experimental design was completely randomized in a factorial $3 \times 3+1$, with five replications. The second experimental step was transplanting the seedlings to the greenhouse, with the combinations of grafting 'Maxifort', 'Multifort', selfgraft and ungrafted, considering the plots combinations of grafting and the subplots the four collection periods 30 60, 90 and 120 days after transplanting. The experimental design was a randomized block in a split plot scheme, each experimental plot consisted of six plants, with six replications. The results of the first stage showed an increase in the activity of POXs and PPO during grafting fixation with rootstocks 'Maxifort', 'Multifort' and also in the selfgraft. In the second stage, there was a higher increase in SOD and POXs activity for the rootstock 'Multifort' at 120 days after transplanting. The grafted and ungrafted plants showed no signs of incompatibility, and the increased enzyme activity attributed to the healing process and lignification of grafted seedlings, having kept this behavior over the cycle of growth and development of tomato plants.

Keywords: Solanum lycopersicum, compatibility, superoxide dismutase, peroxidase, polyphenol oxidase.

\section{(Recebido para publicação em 13 de março de 2015; aceito em 3 de março de 2016) (Received on March 13, 2015; accepted on March 3, 2016)}

\begin{abstract}
A enxertia é uma técnica da horticultura praticada há muitos anos, em diversas partes do mundo, com o intuito de atenuar diversos problemas de origem abiótica e biótica, dentre eles salinização, absorção de nutrientes,
\end{abstract}

toxicidade por metais pesados, ataque de patógenos do solo, além de proporcionar aumentos de produtividade.

O início do emprego desta técnica ocorreu na Coréia e no Japão no final da década de 20, em plantas de melancia enxertadas sobre portaenxertos de abóboras (Rivero et al., 2003). No Brasil, a enxertia em tomateiro, se destaca como importante ferramenta para o manejo em áreas infestadas por patógenos, viabilizando seu cultivo por meio de 
portaenxertos resistentes.

Dentre as culturas comumente enxertadas, destaca-se o tomateiro, uma das hortaliças mais consumidas no mundo e a sétima cultura mais importante na alimentação mundial (Bergougnoux, 2013). Dados da FAO mostram que a produção brasileira no ano de 2011 foi de aproximadamente 4,4 milhões de toneladas, com área colhida de 71.473 ha, fazendo do Brasil o oitavo maior produtor mundial (FAO, 2013); contudo, a produtividade brasileira ainda é relativamente baixa, comparada à de países com alta tecnologia de produção.

Assim, a técnica da enxertia se configura como uma alternativa para aumento da produtividade agrícola do tomateiro, por meio do uso de portaenxertos que proporcionam aumento da produtividade, devido à vigorosa capacidade de absorção de nutrientes e prevenção de infecção por patógenos.

No entanto, é importante ressaltar que o sucesso da enxertia, sob o ponto de vista fisiológico, leva em consideração fatores que proporcionem perfeita soldadura entre enxerto e portaenxerto, destacando-se a avaliação da compatibilidade. Nos estudos de compatibilidade em plantas enxertadas, o aumento dos teores das enzimas antioxidantes ocorre em resposta à defesa ao estresse oxidativo, acionando o mecanismo bioquímico enzimático para neutralizar a produção de espécies reativas de oxigênio (ERO) e permitir o crescimento das plantas enxertadas, visto que a mesma ocasiona forte dano mecânico nas plantas.

Pesquisas evidenciaram que a quantificação da atividade de enzimas antioxidantes pode ser indicativo da existência de compatibilidade ou incompatibilidade entre enxerto e portaenxerto, tornando-se então importantes indicadores nos processos fisiológicos e bioquímicos de união entre enxerto e portaenxerto (Zarrouk et al., 2010; Canas et al., 2014).

Estudos relatados na literatura com diversas espécies de frutíferas e olerícolas (Rodrigues et al., 2001; Kohatsu et al., 2013) mostram essa relação entre a atividade enzimática e a compatibilidade entre enxerto e portaenxerto, haja vista que quanto mais similar a atividade enzimática entre esses materiais vegetais, menores serão os problemas de incompatibilidade.

Além da compatibilidade ou incompatibilidade, essas enzimas também são relatadas na literatura, especialmente, como biomarcadores de diversos estresses em plantas (Jaleel et al., 2009; Ahmad et al., 2010). Peroxidase (POXs, EC 1.11.1.7), polifenoloxidase (PPO, EC 1.10.3.1) e superóxido dismutase (SOD, EC 1.15.1.1), entre outras, estão incluídas no complexo sistema enzimático antioxidante (Sanchéz-Rodriguez et al., 2013), e que podem indicar a existência ou não de compatibilidade entre enxerto e portaenxerto.

É importante ressaltar também, que existem diversos níveis de incompatibilidade e que os mesmos podem se expressar não apenas na fase de muda, mas também durante o desenvolvimento da cultura no campo.

Dessa forma, diante do exposto, o presente trabalho teve por objetivos avaliar a influência da enxertia na expressão da compatibilidade e atividade antioxidante em plantas enxertadas de tomateiro, bem como na produtividade de frutos.

\section{MATERIAL E MÉTODOS}

O trabalho foi realizado em duas etapas experimentais, em casa de vegetação, situada no Setor de Olericultura e Plantas Aromático-medicinais da Faculdade de Ciências Agrárias e Veterinárias, Câmpus Jaboticabal, São Paulo, Brasil (2114'05'S; 48 17'09'O, altitude 614 $\mathrm{m})$, no período de junho a novembro de 2012.

As médias de temperatura e umidade relativa do ar (UR) na casa de vegetação, durante os meses de condução do experimento foram junho $\left(25,2^{\circ} \mathrm{C}\right.$ e UR $65,8 \%)$; julho $\left(18,3^{\circ} \mathrm{C}\right.$ e UR $\left.56,2 \%\right)$; agosto $\left(19,6^{\circ} \mathrm{C}\right.$ e UR 56,7\%); setembro $\left(20,8^{\circ} \mathrm{C}\right.$ e UR $\left.59,7 \%\right)$; outubro $\left(29,4^{\circ} \mathrm{C}\right.$ e UR $56,8 \%)$ e novembro $\left(25,7^{\circ} \mathrm{C}\right.$ e UR 59,8\%).

Foram utilizados dois portaenxertos, Maxifort ${ }^{\circledR}$ e Multifort ${ }^{\circledR}$, ambos provenientes da empresa De Ruiter. Como enxerto foi utilizado o híbrido Alambra $^{\circledR}$, da empresa Clause Tezier. A semeadura dos enxertos e portaenxertos de plantas de tomateiro foi realizada em bandejas de poliestireno expandido, contendo 128 células, preenchidas com substrato comercial Bioplant ${ }^{\circledR}$. Após 10 dias da semeadura dos portaenxertos procedeu-se à semeadura dos enxertos, para que no momento da enxertia houvesse semelhança nos diâmetros. Após as semeaduras, as bandejas foram acondicionadas em casa de vegetação, as quais receberam irrigação duas a três vezes ao dia.

O método de enxertia adotado foi de garfagem em fenda simples, quando as mudas apresentavam cerca de 30 dias e aproximadamente $3 \mathrm{~mm}$ de diâmetro, sendo realizadas no total 70 enxertias para cada tratamento.

A primeira etapa experimental consistiu na avaliação, aos seis e onze dias após a enxertia, das mudas enxertadas e não enxertadas com três combinações de enxertia (Maxifort, Multifort e autoenxertia), em três regiões de coleta no caule: a) $2 \mathrm{~cm}$ acima da região da enxertia (RE1); b) na região de enxertia (RE2) e c) $2 \mathrm{~cm}$ abaixo da região da enxertia (RE3), além do tratamento adicional, constituído de mudas não enxertadas de 'Alambra' (pé franco). O delineamento experimental adotado foi inteiramente casualizado, em esquema fatorial $3 \times 3+1$ e cinco repetições.

Já o delineamento da segunda etapa experimental foi em blocos casualizados, em esquema de parcela subdividida, onde cada parcela foi constituída de seis plantas com as combinações da enxertia (Maxifort, Multifort, Autoenxertia e pé franco) e subparcelas de quatro períodos de coleta $(30,60,90$ e 120 dias após o transplantio). Nesta etapa, a atividade enzimática foi avaliada em folhas totalmente expandidas das quatro plantas centrais. Foram realizadas seis repetições.

As plantas conduzidas nesta etapa, foram cultivadas em vasos plásticos de 13 L preenchidos com fibra da casca de coco, sob casa de vegetação tipo arco, com $51 \mathrm{~m}$ de comprimento e $14 \mathrm{~m}$ de largura, pé direito de $3,5 \mathrm{~m}$, coberta com filme plástico transparente de polietileno com 150 micras, proteção lateral com tela de sombreamento $50 \%$, utilizando o espaçamento 2,0 m entre linhas e 0,40 $\mathrm{m}$ entre plantas. Foram conduzidas duas 
Tabela 1. Atividade enzimática de peroxidases (POXs) e polifenoloxidase (PPO) em mudas de tomateiros, enxertadas e pé franco, em duas avaliações após a enxertia (em dias), 6 e 11 DAE \{enzymatic activity of peroxidases (POXs) and polyphenol oxidase (PPO) on tomato seedlings grafted and ungrafted, on two assessments after grafting (in days), 6 and 11 DAE . Jaboticabal, UNESP, 2013.

\begin{tabular}{|c|c|c|c|c|}
\hline \multirow[t]{2}{*}{ Portaenxertos (PE) } & \multicolumn{2}{|c|}{$\begin{array}{c}\text { POXs ( } \mu \mathrm{mol} \mathrm{de} \mathrm{H}_{2} \mathrm{O}_{2} / \mathrm{min} / \mathrm{mg} \text { de } \\
\text { proteína) }\end{array}$} & \multicolumn{2}{|c|}{$\begin{array}{c}\text { PPO ( } \mu \text { mol purpurogalina } / \mathrm{min} / \mathrm{mg} \text { de } \\
\text { proteína) }\end{array}$} \\
\hline & 06 DAE & 11 DAE & 06 DAE & 11 DAE \\
\hline Maxifort & $0,73 \mathrm{~b}$ & $0,62 \mathrm{~b}$ & $1,01 \mathrm{~b}$ & $1,08 \mathrm{a}$ \\
\hline Multifort & $0,94 \mathrm{~b}$ & $0,67 \mathrm{ab}$ & $1,54 \mathrm{a}$ & $0,57 \mathrm{~b}$ \\
\hline Autoenxertia & $1,93 \mathrm{a}$ & $0,78 \mathrm{a}$ & $1,54 \mathrm{a}$ & $0,66 \mathrm{~b}$ \\
\hline Teste $\mathrm{F}$ & $23,30^{* *}$ & $4,03^{*}$ & $21,88^{* *}$ & $5,90 * *$ \\
\hline \multicolumn{5}{|l|}{ Regiões de enxertia (RE) } \\
\hline RE1 (2 cm acima da enxertia) & $0,54 \mathrm{~b}$ & $0,27 \mathrm{c}$ & $1,02 \mathrm{c}$ & $0,57 \mathrm{~b}$ \\
\hline RE2 (na região da enxertia) & $2,44 \mathrm{a}$ & $1,26 \mathrm{a}$ & $1,92 \mathrm{a}$ & $0,97 \mathrm{a}$ \\
\hline RE3 (2cm abaixo da enxertia) & $0,62 \mathrm{~b}$ & $0,53 \mathrm{~b}$ & $1,24 \mathrm{~b}$ & $0,77 \mathrm{ab}$ \\
\hline Teste F & $65,96^{* *}$ & $146,20 * *$ & $73,73^{* *}$ & $3,15 \mathrm{~ns}$ \\
\hline PE $x$ RE & $18,03 * *$ & $15,18 * *$ & $5,97^{* *}$ & $2,60 \mathrm{~ns}$ \\
\hline Pé franco (trat. adic.) & 0,41 & 0,16 & 0,67 & 0,35 \\
\hline $\mathrm{CV}(\%)$ & 3,43 & 1,61 & 1,74 & 3,91 \\
\hline
\end{tabular}

Médias seguidas de mesma letra na coluna para cada fator, não diferem significativamente pelo teste de Tukey $(\mathrm{p}<0,05)($ means followed by the same letter in the column of each factor do not differ significantly, Tukey test, $5 \%$ ).

Tabela 2. Atividade enzimática da superóxido dismutase (SOD) e peroxidases (POXs), em folhas de tomateiro, enxertado e pé franco \{enzymatic activity of superoxide dismutase (SOD) and peroxidase (POXs) in leaves of grafted and ungrafted tomato plants \}. Jaboticabal, UNESP, 2013.

\begin{tabular}{|c|c|c|}
\hline Portaenxertos (PE) & SOD (U/mg proteína) & $\begin{array}{l}\text { POXs (umol de } \mathrm{H}_{2} \mathrm{O}_{2} / \\
\mathrm{min} / \mathrm{mg} \text { proteína) }\end{array}$ \\
\hline Maxifort & $28,62 \mathrm{a}$ & $0,99 \mathrm{a}$ \\
\hline Multifort & $46,87 \mathrm{a}$ & $1,05 \mathrm{a}$ \\
\hline Autoenxertia & $30,00 \mathrm{a}$ & $0,97 \mathrm{a}$ \\
\hline Pé franco & $31,71 \mathrm{a}$ & $0,97 \mathrm{a}$ \\
\hline Teste F & $2,33^{\mathrm{ns}}$ & $0,56^{\mathrm{ns}}$ \\
\hline DMS & 22,62 & 0,22 \\
\hline \multicolumn{3}{|l|}{ Épocas (E) } \\
\hline 30 & $11,79 \mathrm{~b}$ & $0,69 \mathrm{~b}$ \\
\hline 60 & $13,16 \mathrm{~b}$ & $0,78 \mathrm{~b}$ \\
\hline 90 & $45,91 \mathrm{a}$ & $0,88 \mathrm{~b}$ \\
\hline 120 & $66,33 \mathrm{a}$ & $1,64 \mathrm{a}$ \\
\hline Teste F & $21,60 * *$ & $40,02 * *$ \\
\hline DMS & 21,35 & 0,26 \\
\hline PE x E & $2,38 *$ & $0,66^{\mathrm{ns}}$ \\
\hline $\mathrm{CV}(\%)$ & 27,33 & 26,01 \\
\hline
\end{tabular}

Médias seguidas de mesma letra na coluna para cada fator, não diferem significativamente pelo teste de Tukey $(\mathrm{p}<0,05)$ (means followed by the same letter in the column of each factor do not differ significantly, Tukey test, $5 \%$ ).

hastes para cada lado da linha de plantio, com inclinação de $45^{\circ}$, até atingirem a altura de 2,0 $\mathrm{m}$ do solo, quando foi realizada a poda apical. A desbrota e o amarrio das hastes foram realizados semanalmente. $\mathrm{O}$ método de fertirriga- ção utilizado foi por gotejamento, sendo fixados dois gotejadores por vaso.

Para a realização das análises, foram coletadas amostras de $2 \mathrm{~cm}$ de caule de mudas enxertadas e não enxertadas (primeira etapa) e amostras da quarta folha abaixo do ápice caulinar (segunda etapa), as quais foram acondicionados em recipientes de poliestireno contendo nitrogênio líquido e armazenadas em ultrafreezer a $80^{\circ} \mathrm{C}$ negativos.

Na primeira etapa experimental, foi realizada a determinação da atividade enzimática das peroxidases (POXs, EC 1.11.1) e da polifenoloxidase (PPO, EC 1.10.3.1) em amostras caulinares. $\mathrm{Na}$ segunda etapa a determinação das POXs e superóxido dismutase (SOD, EC 1.15.1.1) foi realizada em amostras foliares. Em ambas as etapas, primeiramente foram obtidos os extratos enzimáticos, utilizando-se o método de Ekler et al. (1993).

A atividade das POXs foi determinada segundo a metodologia de Teisseire \& Guy (2000), sendo a atividade específica expressa em $\mu \mathrm{mol}$ de $\mathrm{H}_{2} \mathrm{O}_{2} / \mathrm{min} / \mathrm{mg}$ de proteína. A atividade da PPO foi determinada de acordo com Kar \& Mishra (1976) expressa em $\mu \mathrm{mol}$ de purpurogalina/min $/ \mathrm{mg}$ de proteína.

Na primeira etapa também ava- 


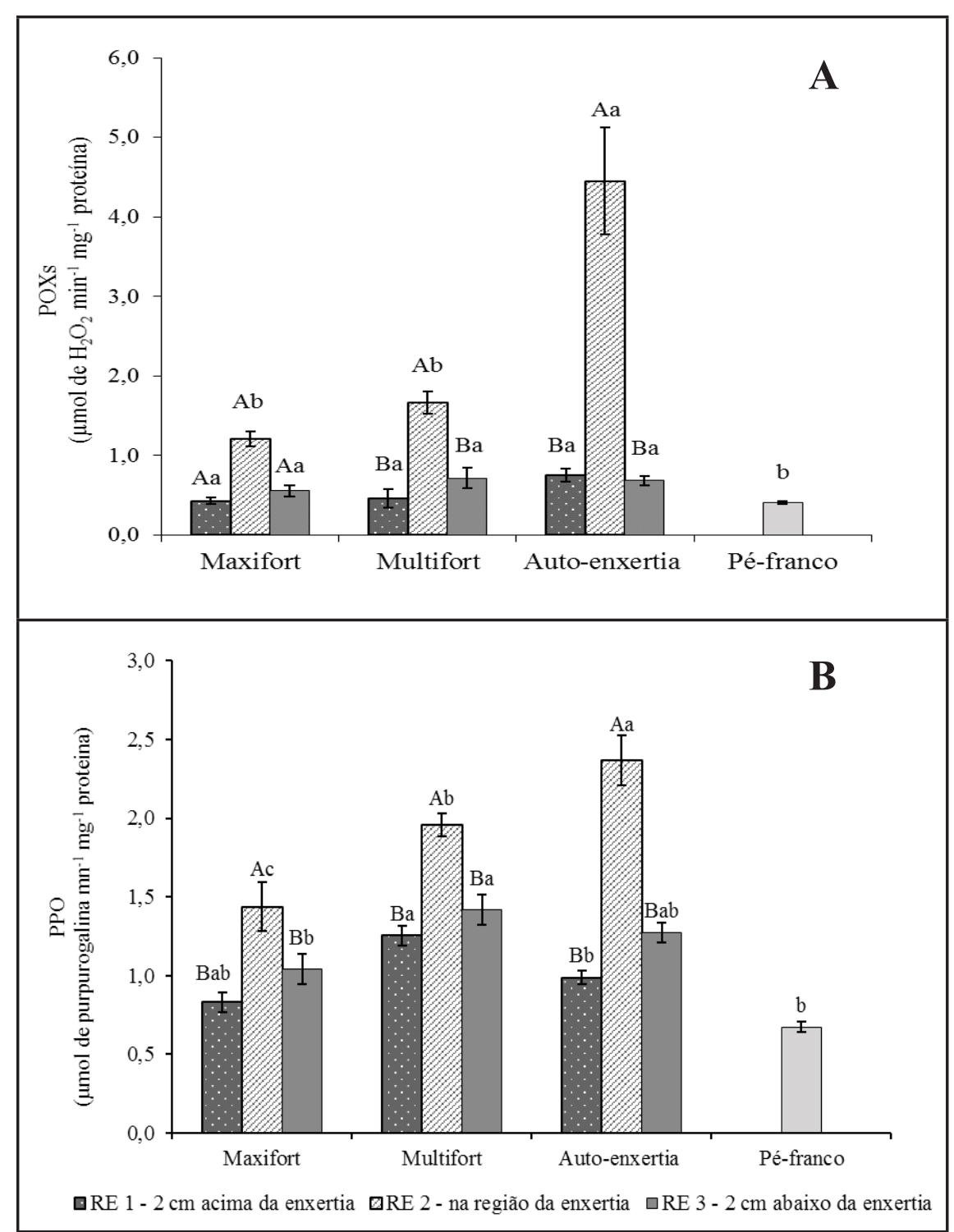

Figura 1. Atividade das peroxidases (POXs) e polifenoloxidase (PPO) em mudas de tomateiro, enxertados e pé franco (não enxertado), aos seis dias após a enxertia. Médias seguidas da mesma letra maiúscula comparam as regiões de enxertia, e letras minúscula comparam os portaenxertos, não diferem entre si pelo teste de Tukey $(\mathrm{P}>0,05)$ \{peroxidase (POXs) and polyphenol oxidase (PPO) activity on grafted tomato seedlings and ungrafted (non-grafted) ones on the $6^{\text {th }}$ day after emergence. Means followed by the same uppercase letter (grafting regions) and lowercase letter (rootstocks) do not differ, Tukey test, $5 \%$. Jaboticabal, UNESP, 2013.

liou-se o percentual de pegamento das enxertias, obtido com base na contagem dos enxertos sobreviventes aos 11 dias após a enxertia.

Para a segunda etapa, foi avaliada a atividade da SOD, determinada segundo o método de Beauchamp \& Fridovich (1973), expressa em U/mg de proteína. Neste caso, uma unidade (U) representa a quantidade de enzima necessária para inibir em $50 \%$ a razão de redução do NBT (Nitroblue Tetrazolium), e também número de plantas por hectare $(12.500$ plantas) e a produção por planta.

O tratamento estatístico foi realizado mediante o emprego da análise de variância e as médias foram comparadas pelo teste de Tukey a $5 \%$ de probabilidade, utilizando-se o programa estatístico AGROESTAT (Barbosa \& Maldonado Júnior, 2015).

\section{RESULTADOS E DISCUSSÃO}

$\mathrm{Na}$ Tabela 1 são apresentados os resultados da análise de variância referente às enzimas peroxidases (POXs) e polifenoloxidase (PPO) (primeira etapa experimental). Verifica-se que a atividade enzimática das peroxidases (POXs) e polifenoloxidase (PPO) aos seis e onze dias após a enxertia (DAE) apresentam interação significativa entre os fatores portaenxertos e regiões de coleta no caule.

Aos seis dias após a enxertia (Figura $1 \mathrm{~A}$ e 1B) verifica-se aumento significativo na atividade das POXs e da PPO na região de enxertia RE2, quando comparado com mudas não enxertadas (pé franco). Tais resultados indicam que o aumento observado pode ser oriundo do estresse mecânico causado pelo uso da técnica, e posteriormente o início do processo de cicatrização e lignificação.

Analisando somente a atividade das POXs (Figura 1A) é possível observar que quando compara-se os portaenxertos, as maiores atividades são observadas na autoenxertia e em 'Multifort'. Já na comparação entre as regiões de coleta, observa-se diferenças significativas para a atividade na região RE2, comparando-se com as demais regiões dos respectivos portaenxertos. Kohatsu et al. (2013) também constaram no sétimo dia após a enxertia, que o incremento das POXs na região mediana do enxerto é devido à lignificação em resposta ao ferimento da enxertia.

$\mathrm{Na}$ PPO (Figura 1B), analisando-se a comparação entre os portaenxertos $\mathrm{e}$ as regiões de enxertia, é possível notar maiores atividades com diferenças significativas para 'Multifort' na região RE2. A maior atividade observada na região da enxertia pode ser uma resposta esperada, visto que este é local de ocor- 


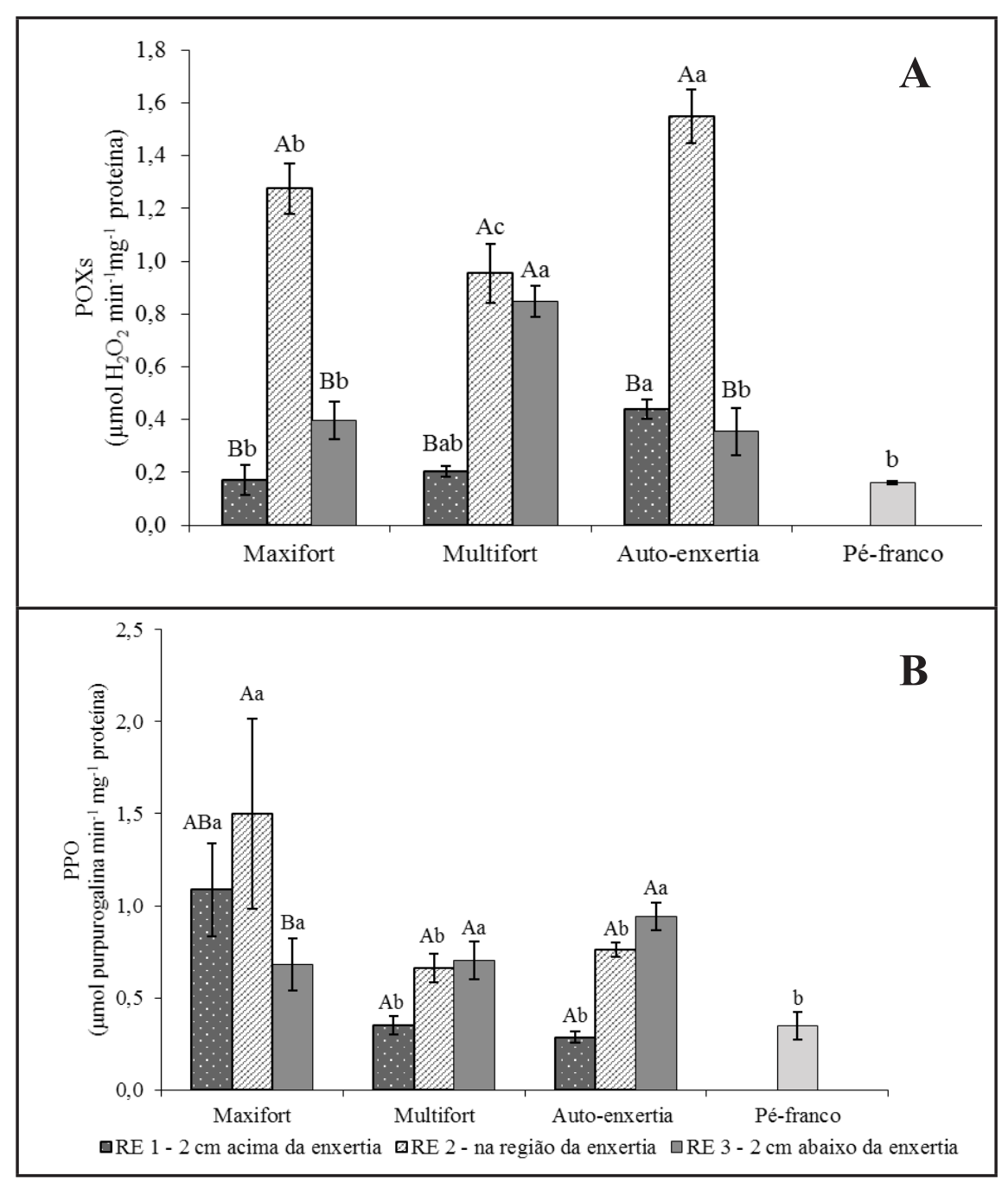

Figura 2. Atividade da peroxidase (POXs) e polifenoloxidase (PPO) de mudas de tomateiro enxertadas e pé franco (não enxertado) no $11^{\circ}$ dias após a enxertia. Médias seguidas da mesma letra maiúscula (regiões de enxertia) e minúscula (portaenxertos) não diferem entre si pelo teste de Tukey $(\mathrm{P}>0,05)$ \{peroxidase (POXs) and polyphenol oxidase (PPO) activity of tomato seedlings grafted and ungrafted on the $11^{\text {th }}$ day after emergence. Means followed by the same capital letter (grafting regions) and small letter (rootstocks) do not differ by Tukey test, 5\% \}. Jaboticabal, UNESP, 2013.

Tabela 3. Produção por planta (PP) e produtividade comercial estimada (PCE), para a cultura do tomateiro enxertada em diferentes portaenxertos \{production per plant (PP) and estimated marketable productivity (PCE) for the tomato crop grafted on different rootstocks $\}$. Jaboticabal, UNESP, 2013.

\begin{tabular}{lcc}
\hline Portaenxertos & PP (kg/planta) & PCE (t/ha) \\
\hline Maxifort & $11,29 \mathrm{a}$ & $141,06 \mathrm{a}$ \\
Multifort & $12,37 \mathrm{a}$ & $154,55 \mathrm{a}$ \\
Autoenxertia & $11,76 \mathrm{a}$ & $147,07 \mathrm{a}$ \\
Pé franco & $10,94 \mathrm{a}$ & $136,68 \mathrm{a}$ \\
\hline Teste F & $2,33^{\text {ns }}$ & $2,31^{\text {ns }}$ \\
DMS & 1,66 & 20,76 \\
CV $(\%)$ & 8,60 & 8,61 \\
\hline
\end{tabular}

Médias seguidas de mesma letra na coluna para cada fator, não diferem significativamente pelo teste de Tukey $(\mathrm{p}<0,05)$ (means followed by the same letter in the column of each factor do not differ significantly, Tukey test, $5 \%$ ). rência da cicatrização e soldadura dos vasos condutores (Vrcek et al. (2011). Além disto, quando comparamos as atividades das mudas enxertadas com as não enxertadas, nota-se claramente que as enxertadas apresentam maior atividade, decorrente provavelmente da cicatrização.

No décimo primeiro dia após a enxertia, a atividade das POXs (Figura 2A) na comparação entre os portaenxertos e as regiões de coleta, evidenciam diferenças significativas para os tratamentos com a autoenxertia na região RE2. Já para a PPO (Figura 2B) observa-se maiores diferenças estatísticas na atividade de 'Maxifort' na região de coleta RE2. Com relação ao pé franco, o mesmo apresentou menor atividade para ambas às enzimas.

É possível inferir que o aumento na atividade das enzimas POXs e PPO, deve-se ao fato das mesmas estarem relacionadas com o processo de lignificação dos tecidos e vasos condutores, além de atuarem também como resposta ao estresse mecânico. Esses resultados também evidenciam a expressão dessas enzimas na compatibilidade entre enxerto e portaenxerto, que juntamente com os resultados de $100 \%$ de pegamento obtidos nas mudas enxertadas, indicam esses serem importantes fatores fisiológicos e bioquímicos da compatibilidade na enxertia.

Trabalhos de Quesada \& Macheix (1984) indicam que cultivares de damasco compatíveis apresentaram maior atividade das POXs quanto maior a lignificação no ponto da enxertia do que as cultivares incompatíveis. Pina \& Errea (2005) também concluíram que, quanto maior a similaridade, maior é a compatibilidade na enxertia, isto é, quanto mais similares forem as peroxidases das plantas, raramente se encontram problemas de incompatibilidade. Resultados esses corroborados no presente trabalho, visto que as mesmas participaram na expressão da compatibilidade, aliado ao excelente pegamento das mudas enxertadas.

Na Tabela 2 encontram-se os resultados obtidos para as enzimas peroxidases (POXs) e polifenoloxidase (PPO) avaliadas ao longo do crescimento e desenvolvimento do tomateiro (Etapa 


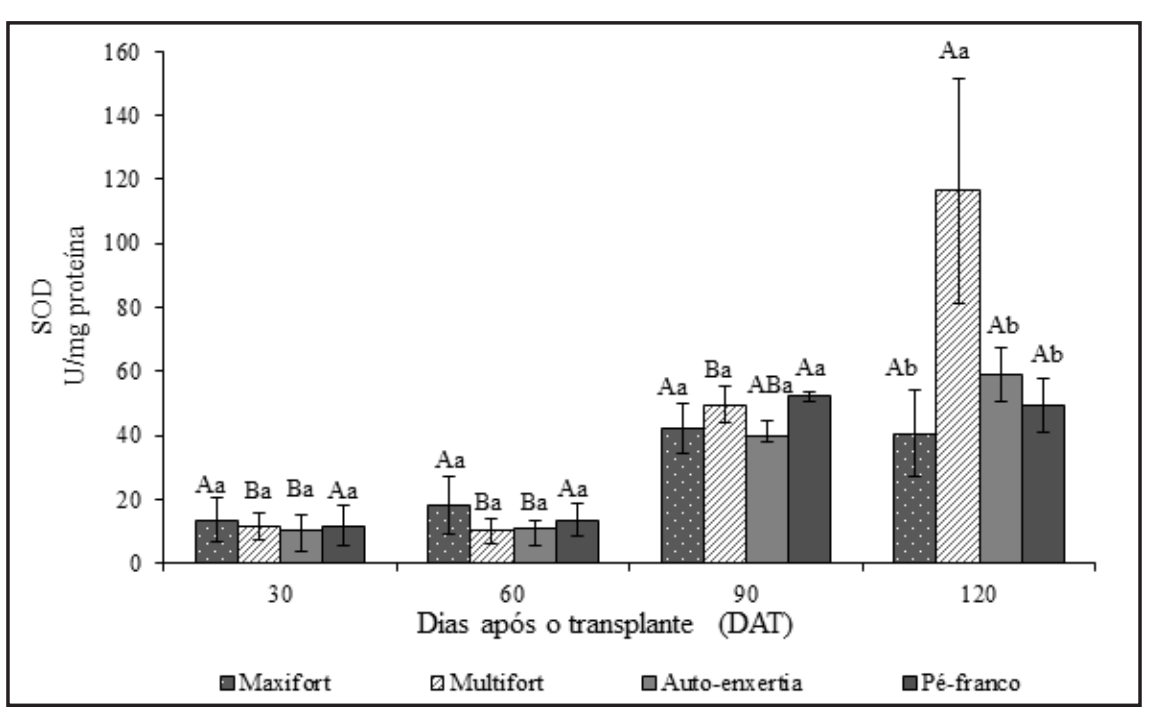

Figura 3. Atividade da superóxido dismutase (SOD) em função de portaenxertos e épocas $(30,60,90$ e 120 DAT) em folhas de tomateiro, enxertado e pé franco (não enxertado). Médias seguidas da mesma letra maiúscula comparam épocas, e letras minúsculas comparam portaenxertos, não diferindo entre si pelo teste de Tukey $(\mathrm{P}>0,05)$. DAT: dias após o transplantio activity of superoxide dismutase (SOD) depending on rootstocks and seasons $(30,60,90$ and 120 DAT) on leaves of tomato plants, grafted and ungrafted. Means followed by the same uppercase letter (times) and lowercase letters (rootstocks) do not differ, Tukey test, 5\%) DAT: days after transplanting\}. Jaboticabal, UNESP, 2013.

2). Observa-se que houve interação significativa entre portaenxertos e épocas de avaliação apenas para a atividade da enzima SOD. Para a atividade da SOD (Figura 3) observa-se que apenas aos 120 DAT houve diferença entre os portaenxertos avaliados, sendo que o portaenxerto 'Multifort', foi o que apresentou maiores atividades enzimáticas.

Diversos trabalhos também relatam maiores atividades em plantas enxertadas no final do ciclo da cultura (Alscher et al., 2002; Rivero et al., 2003; Kohatsu, 2010). Esse aumento é atribuído à intensificação do metabolismo durante a fase de alta produção, em que há aumento na translocação de carboidratos das folhas para os frutos, ou mesmo em condições normais de crescimento e desenvolvimento, quando inevitavelmente, são produzidos radicais livres para manter a homeostase do metabolismo.

Para a atividade das POXs observa-se que houve diferença estatística apenas para o fator épocas, onde aos 120 DAT a atividade demonstrou-se superior às demais épocas, com média de 1,64 $\mu \mathrm{mol}$ de $\mathrm{H}_{2} \mathrm{O}_{2} / \mathrm{min} / \mathrm{mg}$ de proteína (Tabela 2). Esses dados corroboram com os encontrados por Wei et al. (2009), os quais observaram maiores atividades da POXs no auge da produção de plantas enxertadas e pé franco para a berinjeleira. Vale ressaltar que nos tomateiros enxertados e pé franco, o aumento da atividade das POXs aos 120 DAT provavelmente deve ter ocorrido devido à fase metabólica de produção dos frutos e consequentemente de rácemos senescentes, visto que o balanço hormonal etileno/auxina e ácido abscísico no processo da senescência, provavelmente, contribuiu para o incremento das POXs.

Pelo fato das plantas não terem manifestado nenhum sinal de incompatibilidade, nem resposta a estresse mecânico, os quais foram evidenciados pelas análises enzimáticas, ao longo do ciclo do tomateiro, observou-se considerável produção e produtividade, inclusive não revelando diferenças estatísticas entre as diferentes combinações de enxertia utilizadas (Tabela 3).

Dessa forma, apesar do estresse mecânico gerado pelo uso da técnica da enxertia, houve boa cicatrização e alto índice de pegamento, sendo o aumento na atividade enzimática decorrente do processo de cicatrização, indicando não haver incompatibilidade. A produção de frutos não foi afetada pela enxertia.

\section{REFERÊNCIAS}

AHMAD, MSA; MUHAMMAD, A; QASIM, A. 2010. Soil salinity as a selection pressure is a key determinant for the evolution of salt tolerance in Blue Panicgrass (Panicum antidotale Retz.). Flora 205: 37-45.

ALSCHER, RG; ERTURK, N.; HEATH, LS. 2002. Role of superoxide dismutases (SODs) in controlling oxidative stress in plants. Journal of Experimental Botany 53: 13311341.

BARBOSA, JC; MALDONADO, JUNIOR, W. 2015. AgroEstat - sistema para análises estatísticas de ensaios agronômicos. Jaboticabal: FCAV/UNESP. 396p.

BEAUCHAMP, CO; FRIDOVICH, I. 1973. Isoenzymes of superoxidase dismutase from wheat germ. Biochimica et Biophysica Acta 317: 50-64.

BERGOUGNOUX, V. 2013. The history of tomato: From domestication to biopharming. Biotechnology Advances 32: 170-189.

BRADFORD, MM. 1976. A rapid and sensitive method for the quantitation of microgram quantities of protein utilizing the principle of protein-dye binding. Analytical Biochemistry 72: 248-254.

CANAS, S; ASSUNÇÃO, M; BRAZÃO, J; ZANOL, G; EIRAS-DIASJE. 2014. Phenolic compounds involved in grafting incompatibility of Vitis spp: Development and validation of an analytical method for their quantification. Phytochemical Analysis 26: 1-7.

EKLER, Z; DUTKA, F; STEPHENSON, GR. 1993. Safener effects on acetochlor toxicity, uptake, metabolism and glutathione S-transferase activity in maize. Weed Research 33: $311-318$

FAO. 2013. Disponível em: <http://faostat.fao. org/site/339/default.aspx $>$. Acessado em: 05 abr. 2013.

JALEEL, CA; RIADH, K; GOPI, R; MANIVANNAN, P; INÉS, J; AL-JUBURI, HJ; CHANG-XING, Z; HONG-BO, S; PANNEERSELVAM, R. 2009. Antioxidant defense responses: physiological plasticity in higher plants under abiotic constraints. Acta Physiologiae Plantarum 31: 427-436.

KAR, M; MISHRA, D. 1976. Catalase, peroxidase, and polyphenoloxidase activities during rice leaf senescence. Plant Physiology 57: 315-319.

KOHATSU, DS. 2010. Aspectos fisiológicos e bioquímicos da enxertia em plantas de pepino. Botucatu: UNESP-FCA. 61p (Tese doutorado).

KOHATSU, DS; ZUCARELI, V; BRAMBILLA, WP; ONO, EO; SILVA, TRB; RODRIGUES, JD. 2013. Peroxidase and polyphenol oxidase activity on the yield of grafted and ungrafted cucumber plants. African Journal of Agricultural Research 8: 279-283.

LOWRY, OH; ROSEBROUGH, NJ; FARR, AL; RANDALL, RJ. 1951. Protein measurement with the Folin phenol reagent. Journal of Biological Chemistry 193: 265-275.

PINA, A; ERREA, P. 2005. A review of new advances in mechanism of graft compatibilityincompatibility. Scientia Horticulturae 106: 
$1-11$.

QUESADA, MP; MACHEIX, JJ. 1984. Caracterisation d'une peroxydase implique en specifiquement dans la lignification, en relation avec I'incompatibilité au greffage chez I'abricotier. Physiologie Végétale 22: 533-540.

RIVERO, RM; RUIZ, JM; SANCHEZ, M; ROMERO, L. 2003. Does grafting provide tomato plants an advantage against $\mathrm{H}_{2} \mathrm{O}_{2}$ production under conditions of thermal shock? Physiologia Plantarum 117: 44-50.

RODRIGUES, AC; MACHADO, LB; DINIZ, AC; FACHINELLO, JC; FORTES, GRL. 2001. Avaliação da compatibilidade da enxertia em Prunus sp. Revista Brasileira de Fruticultura 23: 359-364.
SANCHÉZ-RODRIGUEZ, E; RUBIOWILHELMI, MM; BLASCO, B; LEYVA, R; ROMERO, L; RUIZ, JM. 2013. Antioxidant response resides in the shoot in reciprocal grafts of drought-tolerant and droughtsensitive cultivars in tomato under water stress. Plant Science 188/189: 89-96.

TEISSEIRE, H; GUY, V. 2000. Copper-induced changes in antioxidant enzymes activities in fronds of duckweed (Lemna minor). Plant Science 153: 65-72.

VRCEK, VI; SAMOBOR, M; BOJIC, M; MEDIC-SARIC, M; VUKOBRATOVICM; ERHATIC, R; HORVATD; MATOTAN, Z. 2011. The effect of grafting on the antioxidant properties of tomato (Solanum lycopersicum
L.). Spanish Journal of Agricultural Research 9: 844-851.

WEI, GP; YANG, LF; ZHU, YL; CHEN, G. 2009. Changes in oxidative damage, antioxidant enzyme activities and polyamine contents in leaves of grafted and nongrafted eggplant seedlings under stress by excess of calcium nitrate. Scientia Horticulturae 120: 443-451.

ZARROUK, O; TESTILLANO, PS; RISUEÑO, MC; MORENO, MA; GOGORCENA, Y. 2010. Changes in cell/tissue organization and peroxidase activity as markers for early detection of graft incompatibility in peach/ plum combinations. Journal of the American Society for Horticultural Science 135: 9-17. 